\title{
Mobile pre-hospital care reorganization during the COVID-19 pandemic: experience report
}

\author{
Reorganização da assistência pré-hospitalar móvel na pandemia de Covid-19: relato de experiência \\ Reorganización de la atención prehospitalaria móvil en la pandemia de Covid-19: relato de vivencia
}

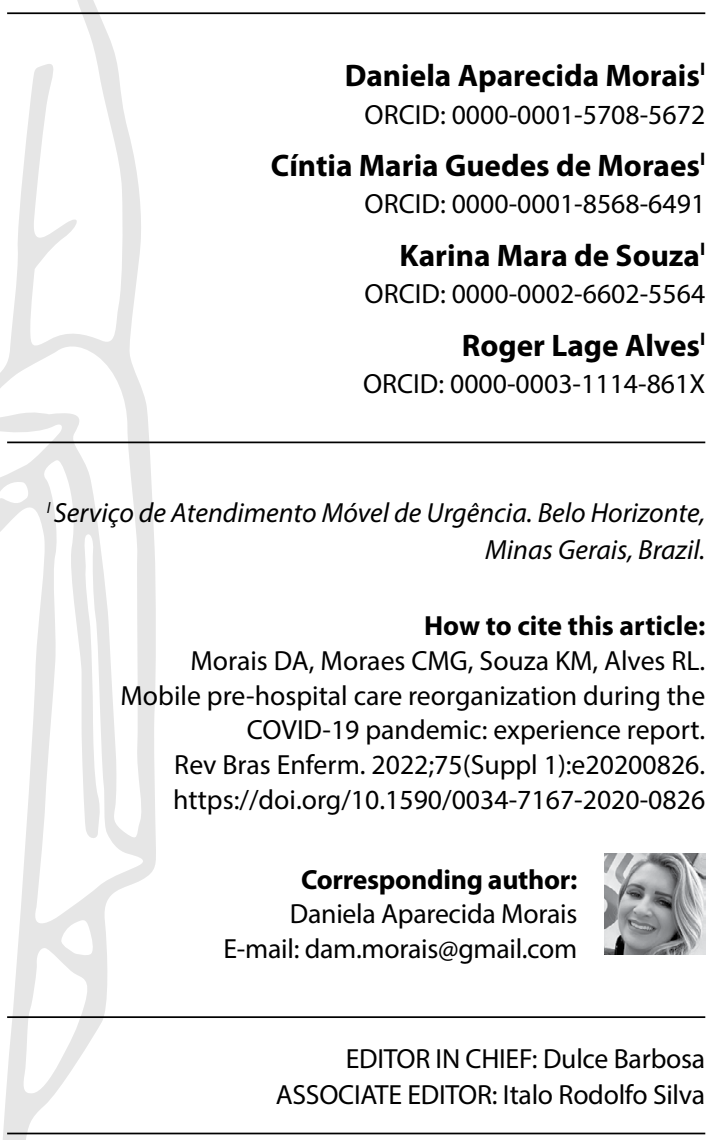

Submission: 08-10-2020
Approval: 06-23-2021

\begin{abstract}
Objective: To describe the reorganization of Belo Horizonte's Mobile Emergency Care Service during the new coronavirus pandemic using the Plan Do-Check-Act quality tool. Methods: Descriptive study, of the experience report type, on the reorganization of care in a mobile pre-hospital care service during the new coronavirus pandemic, from March to July 2020. The Plan-Do-Check-Act quality tool was applied for the process. Results: Preparation of care protocol, meetings, training, addition of ambulances, hiring of professionals, and other actions were carried out, with subsequent evaluation and monitoring. When failures or new needs were identified, actions and changes were implemented while keeping monitoring and evaluation during the work routine. Final considerations: The reorganization of the service through the construction of a protocol and using the Plan-Do-Check-Act as a management tool was essential to promote safe care for professionals and patients.

Descriptors: Emergency Medical Services; Ambulances; Coronavirus Infections; Pandemics; Health Services Administration.
\end{abstract}

\section{RESUMO}

Objetivo: Descrever a reorganização do Serviço de Atendimento Móvel de Urgência de Belo Horizonte durante a pandemia do novo coronavírus, utilizando a ferramenta de qualidade PlanDo-Check-Act. Métodos: Estudo descritivo, do tipo relato de experiência, sobre a reorganização da assistência num serviço de atendimento pré-hospitalar móvel durante a pandemia do novo coronavírus, no período de março a julho de 2020 . Foi aplicada a ferramenta da qualidade Plan-Do-Check-Act para condução do processo. Resultados: Elaboração de protocolo assistencial, reuniões, treinamentos, acréscimo de ambulâncias, contratação de profissionais e outras ações foram realizadas, com subsequente avaliação e monitoramento. Ao serem identificadas falhas ou novas necessidades, ações e mudanças foram implementadas mantendo-se o monitoramento e avaliação na rotina do trabalho. Considerações finais: A reorganização do serviço por meio da construção de um protocolo e tendo como ferramenta de gestão o Plan-Do-Check-Act foi essencial para promover uma assistência segura aos profissionais e aos pacientes.

Descritores: Assistência Pré-Hospitalar; Ambulâncias; Infecções por Coronavirus; Pandemias; Administração de Serviços de Saúde.

\section{RESUMEN}

Objetivo: Describir la reorganización del Servicio de Atención Móvil de Urgencia de Belo Horizonte durante la pandemia del nuevo coronavirus, utilizando la herramienta de calidad Plan-Do-Check-Act. Métodos: Estudio descriptivo, del tipo relato de vivencia, sobre la reorganización de la atención en un servicio de atención prehospitalaria móvil durante la pandemia del nuevo coronavirus, entre marzo a julio de 2020. Fue aplicada la herramienta de la calidad Plan-Do-Check-Act para conducción del proceso. Resultados: Elaboración de protocolo asistencial, reuniones, entrenamientos, incremento de ambulancias, contratación de profesionales y otras acciones fueron realizadas, con subsecuente evaluación y monitoreo. Al ser identificados fallos o nuevas necesidades, acciones y cambios fueron implementados manteniéndose el monitoreo y evaluación en la rutina laboral. Consideraciones finales: La reorganización del servicio por medio de la construcción de un protocolo y teniendo como herramienta de gestión el Plan-Do-Check-Act fue esencial para promover una atención segura a los profesionales y pacientes.

Descriptores: Atención Prehospitalaria; Ambulancias; Infecciones por Coronavirus; Pandemias; Administración de los Servicios de Salud. 


\section{INTRODUCTION}

The discovery of a new type of coronavirus (SARS-CoV-2), after cases of pneumonia in Wuhan, China, left the world on alert, as this virus quickly spread to several countries. Due to its high transmissibility, the World Health Organization (WHO) declared that the outbreak of the disease caused by this virus and called Coronavirus Disease 2019 (COVID-19) constituted a public health emergency, a pandemic ${ }^{(1)}$.

The first confirmed case of COVID-19 in Brazil officially occurred on February 26, 2020, at a time in which countries already facing the pandemic were experiencing health facilities overcrowding, lack of care equipment, and even scarcity or inadequate personal protective equipment use for health professionals, leading to contamination, illness, and even death of these professionals ${ }^{(2)}$.

One of the biggest challenges of COVID-19 is the fact that it is a new pathology. International and national organizations - such as Centers for Disease Control and Prevention (CDC), Ministry of Health (MH), Agência Nacional de Vigilância Sanitária (ANVISA) [National Health Surveillance Agency], among others — have issued recommendations based on the application of influenza contingency plans due to clinical and epidemiological similarities of these diseases. Thus, insufficient knowledge about SARS-CoV-2, its high virulence, associated with the possibility of causing death in infected individuals generate uncertainties about this pandemic, especially among health professionals particularly susceptible to contamination and working in the care of patients with the new coronavirus $\mathrm{s}^{(3-4)}$.

This reality has caused serious impacts on public health, which led to abrupt changes in the organization of health institutions, as well as in the way of assisting people infected by this disease ${ }^{(2)}$.

The experience of different countries has shown a high number of cases of COVID-19. Many of the affected patients may evolve to emergency situations in the extra-hospital environment or require inter-hospital transfers to more complex units, a context in which the Serviço de Atendimento Móvel de Urgência (SAMU) [Mobile Emergency Care Service], a pre-hospital public mobile care service, implemented by the Ministry of Health in 2003, stands out. It is known that mobile pre-hospital care has particularities that can make its professionals more vulnerable during pandemics such as COVID-19(5).

Given the expected increase in demand for health care and the exposure of professionals to the new coronavirus, it was necessary to reorganize the Mobile Emergency Care Service of Belo Horizonte (SAMU-BH) and adapt work processes. The Plan-Do-Check-Act (PDCA) quality tool was chosen, which is a methodology focused on continuous process improvement and is recommended because it is an easy problem-solving guide ${ }^{(6-7)}$.

With a focus on the safety of professionals and patients, all actions were planned based on available technical and scientific evidence, which is frequently evaluated and adjusted, as it is known that the evolution of the pandemic is dynamic, and adaptations will probably be necessary.

\section{OBJECTIVE}

To describe the reorganization of Belo Horizonte's Mobile Emergency Care Service during the new coronavirus pandemic using the Plan Do-Check-Act quality tool.

\section{METHODS}

Descriptive study, of the experience report type, on the reorganization of the SAMU-BH to care for patients with a suspected or confirmed case of COVID-19, from March to July 2020.

SAMU-BH has 21 basic support units (BSU) and 7 advanced support units (ASU), in addition to an emergency medical regulation center. It has about a thousand professionals and performs, on average, 8,700 consultations per month.

To conduct the entire process, the brainstorming technique and the PDCA cycle were adopted, as they allowed to quickly identify the needs and adapt the service to the conditions imposed by the pandemic, considering its dynamic nature.

The brainstorming technique is performed based on a problemquestion, and ideas for solutions are proposed and listed to be later organized and categorized ${ }^{(8)}$.

The PDCA cycle is a tool that consists of a four-stage cyclical repetitive model for continuous improvement in quality management. The letters that make up the method name represent the English verbs To Plan, To Do, To Check, and To Act, respectively ${ }^{(6)}$.

Two studies on the use of PDCA in the context of COVID-19 reported that the application of this methodology was positive, standardized care management, and provided possibilities for applying effective approaches, allowing correction in the event of any need ${ }^{(6-7)}$.

\section{RESULTS - EXPERIENCE REPORT}

After the disclosure of the first confirmed case of COVID-19 in Belo Horizonte, on March 16, 2020, discussions that had begun in February of the same year for the reorganization of the service were intensified. We opted for the construction of a protocol, and initially two nurses were appointed to conduct the entire process of preparing this document.

These nurses, after a meeting using the brainstorming technique based on the question "How to provide safe care to suspected or confirmed patients of COVID-19?", established the items to be addressed in the protocol, the stages of implementation, construction, and the implementation of the recommendations in the service. The PDCA management tool guided the entire service reorganization process and the implementation of the proposed actions (Figure 1).

For the protocol, the following items were defined as essential guidelines to be described, considering the specificities of COVID-19: Principles and Guidelines, Definition of Suspect Cases, Operational Definitions, Organization of Mobile Units, Specificities in the Care of Patients with Suspect or Confirmed Cases of COVID-19, Hand hygiene, Personal Protective Equipment, Equipment and Materials Hygiene, Workers' Health and Risks to Assistance. Flowcharts were also included to facilitate the understanding of the processes and allow for quick consultation by healthcare professionals.

Initially, a free search was carried out on the subject of the defined items to identify literature recommendations that were consistent with the reality of the service. After writing the protocol, the implementation phase of the proposed guidelines began on $03 / 27 / 2020$. 


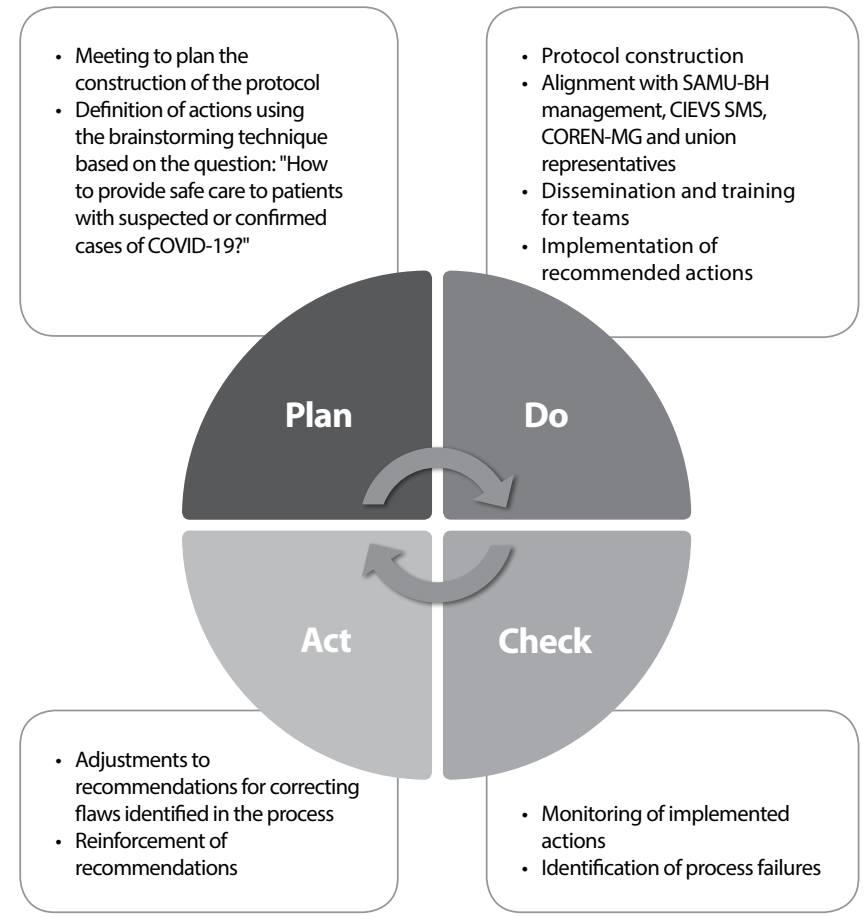

Figure 1 - Items applied to the Plan-Do-Check-Act Cycle for the assistance reorganization process in the Mobile Emergency Care Service of Belo Horizonte during the COVID-19 pandemic, Belo Horizonte, Minas Gerais, Brazil, 2020

It was necessary for all professionals to have access to information and to be aligned with the established recommendations. $A$ wide dissemination was carried out in groups of professionals in the service, and there were many questions and uncertainties.

Meetings involving care teams, service coordination, SAMU-BH management, representative of the Regional Nursing Council of Minas Gerais (COREN-MG), of the Strategic Information Center on Health Surveillance (CIEVS) of the Municipal Secretariat of Belo Horizonte and union representatives were held for the presentation, understanding, and alignment of the proposed actions.

Among the various actions, it was defined that 12 type $A$ vehicles, called "COVID units" and an extra advanced vehicle (COVID advanced support unit - "ASU-COVID") would be allocated to operate exclusively in the inter-hospital transport of suspected or confirmed patients of COVID-19.

It was also established a rotation of BSU and ASU to carry out, preferably, pre-hospital care (PHC) of suspected or confirmed cases of COVID-19, called "PHC-COVID" units. For these units, the quantity of materials and medicines, such as ampoules, equipment, syringes, and splints, was reduced, minimizing the risk of contamination, and facilitating the disinfection process. For the other units, materials were reorganized and protected in order to reduce contamination. Face-to-face training on equipment dressing and undressing began for the teams. Training was disclosed, inviting professionals to participate; and, in order to facilitate the reach, this action was carried out every time the mobile units went to the service's headquarters to replenish materials and medicines in the warehouse. While these were separated by the warehouse staff, the professionals were trained. Nurses from the regulation center $(\mathrm{RC})$ were also trained to guide the teams if necessary.
The nursing coordination established a monitoring and daily follow-up process for professionals with flu-like symptoms and on leave from the service. The e-mail service of the Teaching and Research Center (NEP), the RC nurses, as well as the management group team remained available to answer questions regarding the new implemented routines.

With the implementation of the protocol, the monitoring and evaluation of actions began. For this, the Help Desk was used, an on-line form already available in the service, in which the professionals were able to send suggestions, non-conformities, etc., to the coordination. Problems were reported in the professionals' groups, and reports were also issued. Through these instruments, the need for adjustments in the process was identified. All these demands, when identified, were analyzed; new actions were planned, implemented, monitored, and corrected again if necessary: an ongoing process as proposed by the PDCA cycle.

The first update of the protocol was carried out, considering the analysis made by the Regional Council of Nursing of Minas Gerais (COREN-MG), whose suggestion was to improve the description of actions related to cardiopulmonary resuscitation maneuvers and the use of an oxygen mask with reservoir, as they are aerosol generating procedures. So, it was done as indicated.

Another initial change was in relation to face-to-face training in equipment dressing and undressing, as it was understood that there would be risks in sharing protective equipment for training and, considering the possibility of scarcity of materials as indicated by the world reality, they had to be considered for conscientious use. Then, it was decided that videos would be made about the equipment dressing and undressing as a strategy to guide professionals, which were disseminated in groups and on social networks at the time. Nurses were asked to produce and record these instructional videos; and recommendations regarding the use of personal protective equipment (PPE) and hand hygiene were also reinforced among the teams.

In view of the increase in the number of cases of caring of suspected or confirmed patients of COVID-19, it was decided to exclude the proposal of the "PHC-COVID" units: an abbreviated load map was established in all mobile units, and a nurse was assigned to assist and accompany this change. The secondary RC was divided in such a way that all cases related to COVID-19 were then regulated by specific professionals, unlike the usual secondary regulation of the service. Guidance for professionals working in the RC was intensified in order to reduce the possibilities of SARS CoV 2 transmission among these professionals.

The PPE use and replacement control, especially of the N95 or PFF2 mask, showed failures in the dispensing practice, so that a new flow with the implementation of a control form was created. As for the cleaning of vehicles, interventions were necessary with the contracted company that was already responsible for this activity. Nurses were invited to participate in this process and went to the site to organize the car disinfection flow, the space for professionals' undressing, proper disposal of infectious waste, training of professionals responsible for cleaning the ambulance, among other requirements. After a few weeks, more training was required for new professionals in this location.

New recommendations were published, so there was a need to update the protocol: to increase the safety of professionals in 
mobile units, the main change was to consider as a suspected case every unbeknownst patient or patient with an unbeknownst clinical history.

It was identified that, despite the wide dissemination of the protocol, there was no standardization of actions. Thus, a web conference was held for doctors and nurses, with the aim of addressing the main aspects of the protocol, updates, and answering questions.

For the BSU teams, it was decided to carry out a different action: nurses were invited to provide training, and an orientation script was created to standardize the information. The teams were approached at the service's headquarters, received the necessary guidance and had the opportunity to report the problems experienced during the visits, as well as to resolve any doubts.

The increased demand for inter-hospital transport was having a big impact on the service. It was decided that there would be a return of the BSU-COVID units, but now they would preferentially carry out inter-hospital transport of suspected or confirmed cases of COVID-19, so that all pre-hospital care would be handled by the other BSUs. A weekly, by region, BSU rotation was determined, the ambulance cleaning process was also reorganized, and the BSU teams were trained by nurses. For the ASUs, the usual conduct was maintained: that of providing assistance of any kind.

Despite all the efforts made, in view of the growing demand, indicators showed the need to implement new actions: five ambulances were made available (available number of reserve vehicles) so that teams could swap vehicles and carry out a new care service while the official vehicle was sanitized; the contracted company hired new professionals to assist in vehicle hygiene processes; and also new places to sanitize them were established, in addition to those used by the contracted company and CR; to carry out inter-hospital transport, more professionals were hired to compose advanced support teams and type $A$ units, the latter operating daily from $10 \mathrm{am}$ to $10 \mathrm{pm}$.

\section{DISCUSSION}

The particularities of COVID-19 made the pre-hospital care services organize themselves and carry out changes in the assistance setup to handle demands in care, avoid the contamination of professionals, promote adequate training, and ensure the supplies and other resources necessary for care ${ }^{(9)}$.

This pandemic caused health services to reorganize assistance in an attempt to mitigate the risks of occupational exposure to the new coronavirus. Specifically, in mobile PHC services, an increase in requests for assistance is expected and, unfortunately, a reduction in the number of professionals due to leaves ${ }^{(5)}$.

A protocol is a guide to care work, and its construction must follow some criteria and rules to be properly formulated and obtain a satisfactory result ${ }^{(10)}$. Thus, we tried to comply with these guidelines for the formulation of the problem-question of the protocol discussed in this experience report.

The brainstorming technique allowed the quick identification of problem situations and specificities that would be addressed in the protocol considering the theoretical knowledge available and the practical experience of those involved in the elaboration. At this stage, the involvement of several professionals would be important, but the need for rapid intervention due to the onset of cases in the city prevented this activity. Considerations presented by the service professionals have been continuously analyzed in the protocol review processes.

The SAMU-BH had an elaborate protocol structure, so the authors were responsible for identifying the specific demands related to COVID-19 in order to address the key aspects concerning the change in techniques and behaviors, considering the specificities of mobile PHC.

The protocol was made available electronically to all professionals in the service and on the website of the Municipality of Belo Horizonte, along with the flowcharts of care and equipment dressing and undressing, in the format of a Technical Note from the Municipal Health Department (https://prefeitura.pbh.gov. $\mathrm{br} / \mathrm{sites} /$ default/files/estrutura-de-governo/saude/2020/notatecnica-17.pdf). It was noticed that these documents guided the actions of professionals in the service routine, generating less anxiety in the group of workers.

It was necessary to articulate ways to give teams access to information and knowledge. The face-to-face and small group training strategies gave workers the opportunity to express doubts about the routine and the pathology, as well as facilitated communication between management and workers.

The use of videos allowed professionals to have available and accessible guidance in their daily work, and this strategy was considered to be used for further instructions. A review study carried out with the purpose of evaluating methods and strategies for performing and training equipment dressing/undressing techniques reported that videos can improve skills and that face-to-face instructions can be more effective in ensuring adherence to the trained technique than traditional methods of teaching or just videos ${ }^{(10)}$.

About $80 \%$ of nurses and physicians participated in the web conference held for the presentation and discussion of the protocol. This high percentage of participants evidenced the potential of digital platforms as a resource for service training.

Changes in the epidemiological picture, service indicators, scientific publications, and technical regulations are parameters constantly evaluated to identify the need for revisions to the adopted recommendations.

To direct the entire reorganization of care at SAMU-BH, the authors used the PDCA as a management tool that has been adopted, due to its simplicity, in health institutions to guide the processes ${ }^{(6-8)}$. The use of this methodology was positive because, despite being essentially subjective, it is an easy guide for solving problems.

\section{Study/Report Limitations}

This report presents the experience lived in the initial months of the pandemic, considering the particularities of a public mobile pre-hospital care service in a specific, large municipality, allowing interventions that may or may not be suitable for other locations to be defined and adopted. However, it brings reflections and a work model adaptable to different contexts.

It is not possible to fully assess the actions taken, as they are being implemented and the service is still experiencing new situations imposed by the pandemic and its evolution in the municipality. 


\section{Contributions to the field}

The experience with the use of the PDCA management tool for quickly structuring actions in a service, in response to a situation of large proportions, highlighted the importance of health management. The use of electronic training and communication resources proved to be effective in streamlining and ensuring greater reach of information.

This unprecedented situation and this new pathology present continuous scientific discoveries and findings that update the actions to be taken, since, in coping, the behavior of the cases and the disease within the local reality must be taken into account. In this sense, cycles of assessment, action, and reassessment are useful because they allow the implementation of actions and changes according to the dynamics of the pandemic presentation.

\section{FINAL CONSIDERATIONS}

It is noticed that the reorganization of the service based on the protocol's recommendations was essential for a safer care for professionals and patients.

The use of the PDCA requires constant monitoring of actions and a need for follow-up and discussions for the analyzing and evaluating implemented actions. The use of this management tool was positive, as, despite being essentially subjective, it is an easy guide for solving problems.

TheSAMU-BH reorganization process, up to the moment of finalizing this manuscript, is being implemented. It is expected that, after the COVID-19 pandemic, a new normal will be established in this service to continue providing greater safety to professionals and patients. It is also expected that these workers will rethink the way they assist and maintain the biosafety practices adopted in this pandemic period.

\section{REFERENCES}

1. Belasco AGS, Fonseca CD. Coronavírus 2020. Rev Bras Enferm. 2020;73(2):e2020n2. https://doi.org/10.1590/0034-7167-2020730201

2. Gallasch CH, Cunha ML, Pereira LAS, Silva-Jr JS. Prevention related to the occupational exposure of health professionals workers in the COVID-19 scenario. Rev Enferm UERJ. 2020;28:e49596. https://doi.org/10.12957/reuerj.2020.49596

3. Freitas ARR, Napimoga M, Donalisio MR. Assessing the severity of COVID-19. Epidemiol Serv Saúde. 2020;29(2):e2020119. https://doi. org/10.5123/s1679-49742020000200008

4. Medeiros EAS. Health professionals fight against COVID-19. Acta Paul Enferm. 2020;33:eEDT20200003. https://doi.org/10.37689/ acta-ape/2020edt0003

5. Guimarāes HP, Damasceno MC, Ribera JM, Onimaru A, Malvestio M, Bueno M, et al. Recomendações para o atendimento de pacientes suspeitos ou confirmados de infecção pelo novo coronavírus (SARS-CoV-2) pelas equipes de atendimento pré-hospitalar móvel. Associação Brasileira de Medicina de Emergência (ABRAMEDE)[Internet]. 2020 [cited 2020 May 26]. Available from: http://abramede.com.br/wp-content/ uploads/2020/04/RECOMENDACOES-APH-220420.pdf

6. Li Y, Wang H, Jiao J. The application of strong matrix management and PDCA cycle in the management of severe COVID-19 patients. Crit Care. 2020;24:157. https://doi.org/10.1186/s13054-020-02871-0

7. Chen Y, Zheng J, Wu D, Zhang Y, Lin Y. Application of the PDCA Cycle for Standardized Nursing Management in a COVID-19 Intensive Care Unit. Ann Palliat Med. 2020; 9(3):1198-205. https://doi.org/10.21037/apm-20-1084

8. Santana RM, Souza, ATS. Momento de Investigação. In: Planejamento em Enfermagem: aplicação do processo de enfermagem na prática administrativa. Bahia (Ilhéus): Editus, 2008. 70-86. https://doi.org/10.7476/9788574555294.0011

9. World Health Organization (WHO). Rational use of personal protective equipment (PPE) for coronavirus disease (COVID-19): interim guidance, 19 March 2020. 2020 [cited 2020 Jun 15]. Available from: https://apps.who.int/iris/handle/10665/331498

10. Verbeek J, Rajamaki B, Ljaz S, Sauni R. Personal protective equipment for preventing highly infectious diseases due to exposure to contaminated body fluids in healthcare staff. Cochrane Database System Rev. 2020;7(5). https://doi.org/10.1002/14651858.CD011621.pub5 